\title{
Direct observations and analysis of the spallation of alumina scales grown on PM2000 alloy
}

\author{
P. Lours*, J. Sniezewski, Y. Le Maoult, B. Pieraggi \\ Research Centre on Tools, Materials and Processes, Ecole des Mines d'Albi-Carmaux, 81013 Albi Cedex 9, France
}

\begin{abstract}
The spallation during cooling or thermal cycling of alumina scales grown at high temperature on PM2000 alloy is directly observed and recorded using CCD cameras. This simple and direct method permits to determine easily and accurately the scale spallation kinetics. In addition, it provides many insights on the spallation mechanisms and processes and their evolution as well as on the effect of substrate microstructure on spallation.
\end{abstract}

Keywords: High temperature oxidation; Oxide spallation; Microstructure; ODS alloy; Thermal cycle; In situ analysis

\section{Introduction}

The degradation of oxide scales by cracking or spalling impairs dramatically the life of components exposed to high temperature and more specifically to thermal cycles. Therefore, the characterization of the spallation of thermally grown protective oxides is of utmost concern. Various experimental techniques have been developed to determine the parameters pertinent to describe the spallation behavior of oxide scales. The most commonly considered parameters are the critical temperature and the critical oxide thickness for the onset of spallation [1]. Thermogravimetric analysis is among the most commonly used method to monitor the evolution of specimen mass change during oxidation and thermal shock [2-4] or much less easily during thermal cycles [5]. Such an analysis permits to determine both the critical temperature and the scale thickness. However, thermogravimetry is essentially a macroscopic approach and does not provide precise insight on the processes of oxide scale spallation. Subsequent surface examinations are required to investigate the advance of scale spallation or scale degradation as cracking. Acoustic emission suffers the same limitation and cannot be of course implemented to quantify mass loss during cycling. However, this indirect method is often employed, using associated complex post-treatment of experimental data, to determine

\footnotetext{
* Corresponding author. Tel.: +33 5634930 78; fax: +33 563493242 .

E-mail address: philippe.lours@enstimac.fr (P. Lours).
}

the critical temperature for the onset of spallation. Oxidation in confined crucibles based on a "one specimen per exposure" approach has given interesting results [6]. Indeed, this approach allows the characterization of both the mass change and the microstructural features of spalled area but it remains limited to predict the critical temperature for spallation. In addition, this method requires lots of specimens and is rather tedious to conduct properly.

These different techniques have been often coupled to collect complementary results prone to describe satisfactorily the various thermal, mechanical, environmental and microstructural effects involved in oxide scale spallation [7-9]. However, as the size and shape of the specimens required by all these methods are different, a quantitative comparison of the data to characterize scale spallation is a rather difficult and complex task.

This paper presents the first observations and results obtained by investigating in situ the spallation of thermally grown oxides. The approach is based on the video monitoring, immediately after oxidation in a furnace, of the surface evolution of specimens during cooling out of the furnace, after only one oxidation treatment or after several thermal cycles. Thus, the evolution of the specimen surface after various exposures at high temperature and/or increasing number of cycles is recorded and analyzed using a post-treatment of images extracted from the video monitoring to determine the surface fraction of spalled oxide scale, as a function of either the cooling time or temperature. The main benefit and interest of this in situ method is clearly its ability to determine straightforwardly and accurately: (i) the spalla- 
tion kinetics; (ii) the critical temperatures for different extents of spallation while the scale degradation progresses, through the synchronization of a temperature measurement to the video recording; and (iii) the spallation features and their evolution as a function of time and cycles number. Moreover, this method may also provide additional and interesting insights such as the influence of substrate microstructure and crystal orientation, the size distribution of spalled area, and the spallation mechanisms.

\section{Materials and experimental methods}

The present work was performed on ferritic ODS commercial FeCrAlY alloy PM2000 (20 wt \% Cr, $5.5 \mathrm{wt} \%$ Al, $0.5 \mathrm{wt} \%$ $\mathrm{Ti}, 0.5 \mathrm{wt} \% \mathrm{Y}_{2} \mathrm{O}_{3}$ ). This alloy is an alumina-forming alloy. The specimens, with dimensions $25 \mathrm{~mm} \times 25 \mathrm{~mm} \times 5 \mathrm{~mm}$, are cut from a rolled plate and are therefore highly textured, showing large grain aspect ratio. The largest faces of specimens are normal to the rolling direction. Fig. 1 shows the typical microstructure of these specimen faces. The central coarse grain is present on all studied specimens.

The spallation behavior of alumina scales was studied during the cooling stage of specimens oxidized at $1300{ }^{\circ} \mathrm{C}$ in laboratory air for 194, 267, 362 and $819 \mathrm{~h}$. The thickness of alumina scales, measured on different cross-sections, was respectively 17, 20, 24 and $36 \mu \mathrm{m}$. The corresponding parabolic rate constant is equal to $1.25 \mu \mathrm{m} \mathrm{h}^{-1 / 2}$. After these oxidation treatments, the specimens were taken out of the furnace and directly put on a metallic plate equipped with a thermocouple to immediately record the evo-

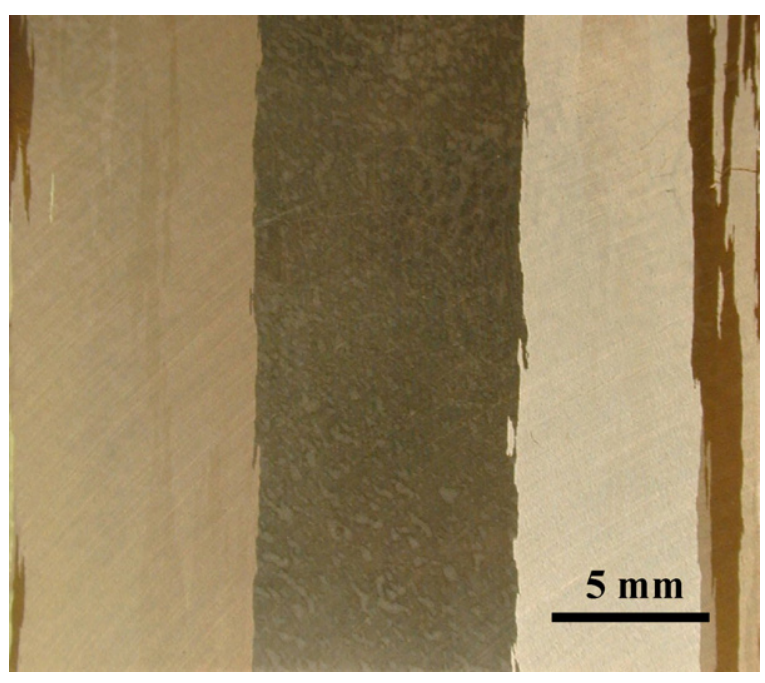

Fig. 1. Microstructure of alloy PM2000.

lution of the surface monitored using a CCD camera normal to the largest specimen face. Such type of specimen holder provides an average cooling rate in natural air of $80^{\circ} \mathrm{C} / \mathrm{min}$. These experiments allow the characterization of the scale degradation during the first cooling stage (first cycle) as a function of time and/or the cooling temperature, monitored concomitantly by the thermocouple. Additional tests devoted to characterize the influence of substrate microstructure and the impact of the cooling rate and thermal gradient through the specimen thickness were conducted following 384,480 and $960 \mathrm{~h}$ exposure at $1300^{\circ} \mathrm{C}$.

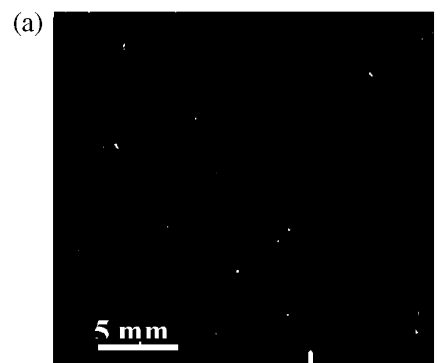

Cooling time $\mathrm{t}=90$ seconds

Specimen temperature $\mathrm{T}=418^{\circ} \mathrm{C}$

Spalled surface fraction $\mathrm{F}=0.1 \%$

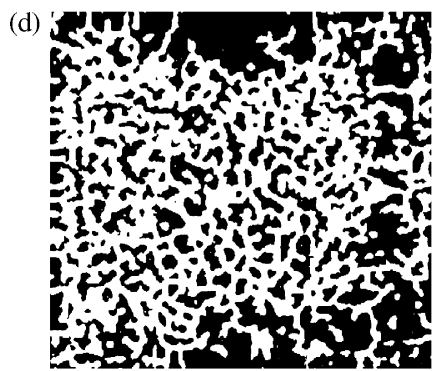

$\mathrm{t}=330 \mathrm{~s}$

$\mathrm{T}=189^{\circ} \mathrm{C}$

$\mathrm{F}=52.5 \%$

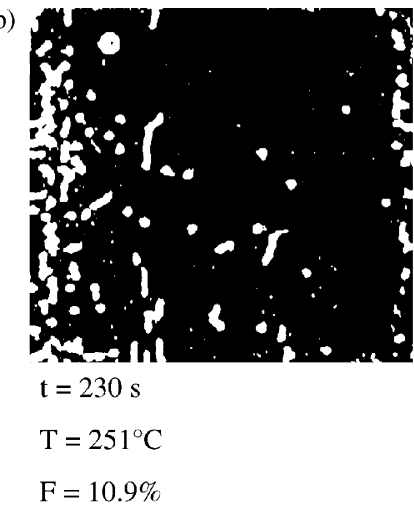

$\mathrm{F}=10.9 \%$

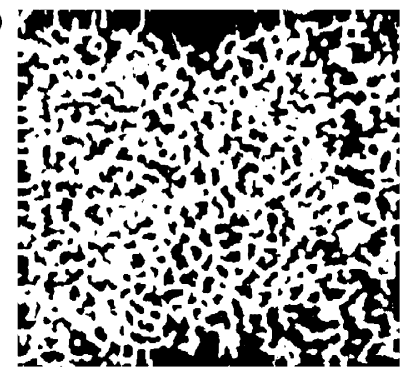

$\mathrm{t}=450 \mathrm{~s}$

$\mathrm{T}=141^{\circ} \mathrm{C}$

$\mathrm{F}=59.3 \%$
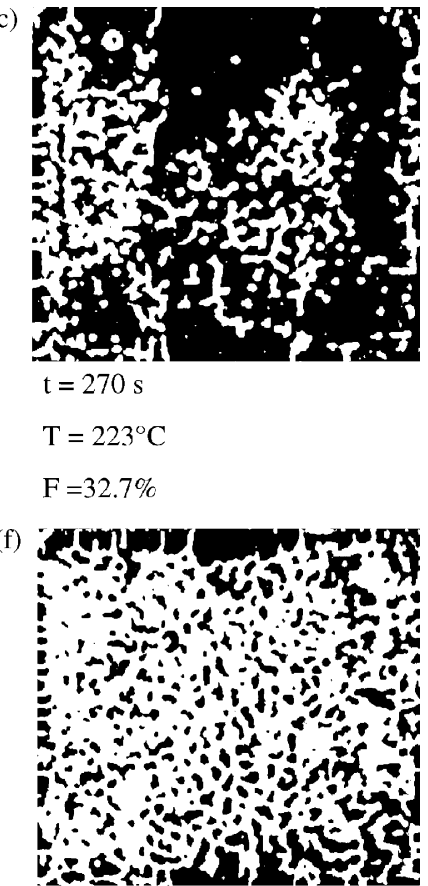

$\mathrm{t}=870 \mathrm{~s}$

$\mathrm{T}=32^{\circ} \mathrm{C}$

$\mathrm{F}=66.5 \%$

Fig. 2. Successive binarized images extracted from a video sequence showing the evolution of spallation (in white) upon cooling PM2000 specimen exposed $384 \mathrm{~h}$ at $1300^{\circ} \mathrm{C}$. 
To investigate the influence of thermal cycling on the behavior of alumina scales, a complex cycle was imposed to the specimen including a succession of elementary short-term exposures $(1 \mathrm{~h}$ holding), medium-term exposures ( $16 \mathrm{~h}$ holding) and long-term exposures ( $80 \mathrm{~h}$ holding) at the temperature of $1300^{\circ} \mathrm{C}$ followed by natural cooling down to $100^{\circ} \mathrm{C}$. The surface evolution was recorded during each cooling period.

The video recording of each test was carefully analyzed to determine the onset of spallation, its location, the size of spalled area, its evolution as a function of time and the effect of thermal cycling on the above parameters. More than 45 successive images were selected and analyzed to determine the kinetics of scale spallation.

\section{Critical temperature and overall spallation kinetics}

The direct observation of the specimen surface during cooling permits, using image analysis, an accurate and continuous determination of both the onset and the kinetics of scale spallation.

The CCD camera focussed on the specimen surface during cooling provides real-time in situ information on the spallation kinetics. Successive images are extracted from the video tape recording and are subsequently treated to derive the instantaneous surface fraction of spall. An example is given in Fig. 2 for a specimen initially exposed at $1300{ }^{\circ} \mathrm{C}$ for $384 \mathrm{~h}$. The figure shows a sequence of binarized images allowing to discriminate, for each time increment or temperature decrement, the spalled zone where oxide has detached, in white contrast, and the apparently undamaged surface in black contrast.

The variations as a function of time of the spalled surface fraction upon cooling, derived from this type of image analysis, are reported in Fig. 3a. The systematic concomitant monitoring of temperature during cooling allows to plot the evolution of the spall surface fraction against temperature as indicated in Fig. 3b. Curves in Fig. 3a and b are both representative of the spallation kinetics of alumina scales grown on PM2000 at $1300^{\circ} \mathrm{C}$ after various long-term exposures. These curves clearly illustrate the influence of the scale thickness on the propensity of the oxide to spall, in agreement with the commonly accepted models for oxide spallation [1,4-7]. Indeed, the magnitude of scale spallation increases and the critical temperature drop for spallation decreases as the scale thickness increases. Furthermore, the spallation curves can be analyzed and fitted to probalistic distributions such as, for instance, log-normal distributions, to determine specific parameters such as the mean temperature corresponding to $50 \%$ of spallation. Such parameters can be quite useful to compare and classify the behavior of alloys submitted to similar tests.

In addition, the analysis of the spallation kinetics permits a quick, accurate and reliable determination of the spalling critical temperature and appears to be easier and more convenient to use than many other physical methods such as, for instance, acoustic emission. Fig. 4 shows the variation of the critical temperature to initiate spallation, measured by image analysis. Note that in the domain of oxide thicknesses explored, this critical temperature is proportional to the exposure time, that is, for an alloy such as

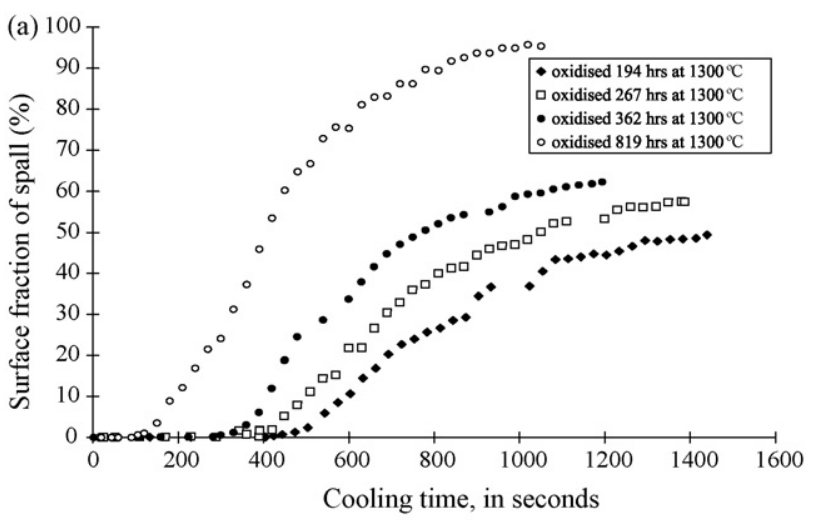

(b)

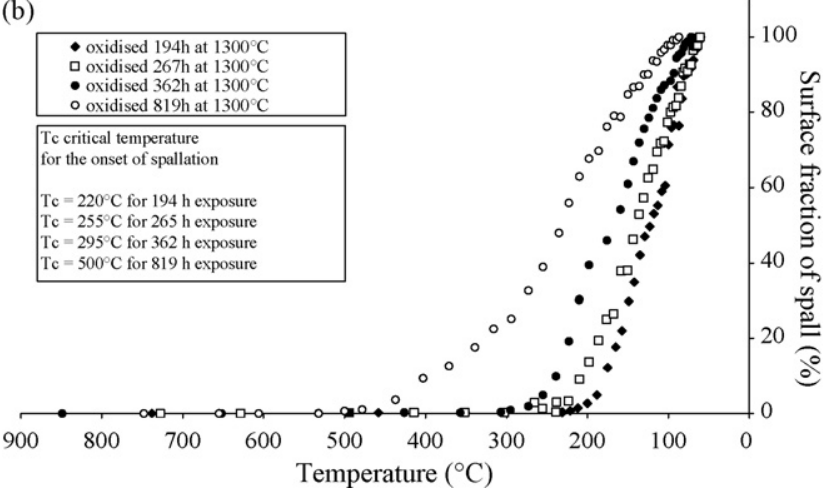

Fig. 3. (a) Gross spallation kinetics upon cooling after various holding time at $1300^{\circ} \mathrm{C}$; (b) normalized surface fraction of spall vs. cooling temperature and critical temperature for the onset of spallation.

PM2000 showing parabolic oxidation kinetics, to the square of the oxide thickness. This proportionality is, for relatively thick scales, representative of spallation by buckling where the critical temperature drop $\Delta T_{\mathrm{c}}$ is, according to the model described in [7], given by

$\Delta T_{\mathrm{c}}=\left(\frac{1.052 \xi^{4}}{R^{4}}+\frac{1.041 \gamma_{\mathrm{f}}}{E_{0} \xi}\right)^{1 / 2} \frac{1}{\Delta \alpha}$,

where $\xi$ is the oxide thickness, $R$ the size of the buckle, $\gamma_{\mathrm{f}}$ the fracture energy of the interface substrate-oxide, $E_{0}$ the Young's

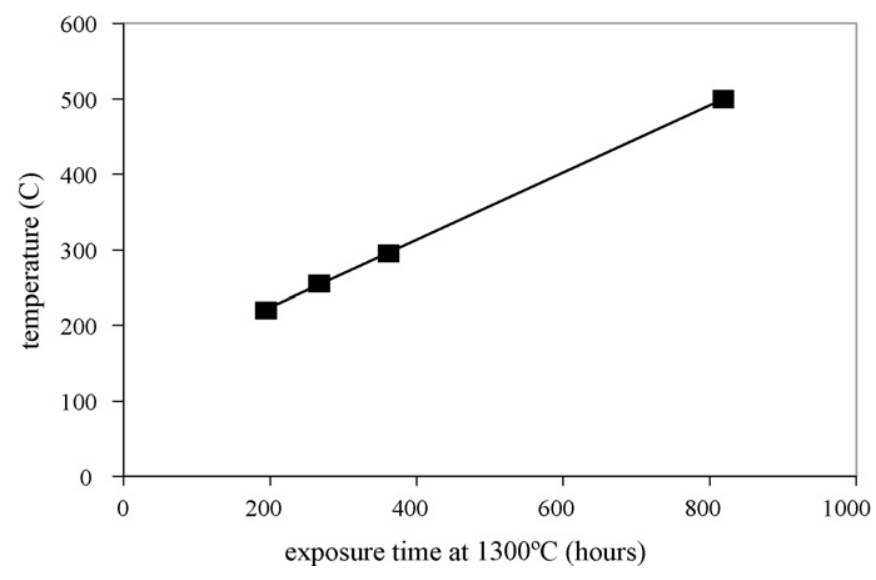

Fig. 4. Critical temperatures for spallation vs. exposure at the oxidation temperature. 
modulus of the oxide and $\Delta \alpha$ is the difference in coefficient of thermal expansion between the substrate and the oxide.

The propensity of the alumina scale grown on alloy PM2000 to spall off by buckling is confirmed by most of the dynamic sequences monitored and that will be discussed in the next section.

This method is particularly useful and seems more accurate than mass loss measurements to determine the critical temperature for spallation [10]. The mass resolution of the technique can be calculated from the capabilities of the optical system used to monitor the spallation events. Considering that the smallest detectable spall accurately corresponds to the size of an elementary pixel of the camera detector (composed of $720 \times 576$ pixel), the mass variation $\Delta m$ can be written as

$\Delta m=\left(\frac{d_{\text {specimen }}}{d_{\text {focal }}}\right)^{2} \delta_{x} \delta_{y} \xi_{\mathrm{o}} \rho_{\mathrm{o}}$,

where $d_{\text {specimen }}$ is the distance from the camera to the specimen, $d_{\text {focal }}$ the focal length of the camera, $\delta_{x}(8.6 \mu \mathrm{m})$ and $\delta_{y}(8.3 \mu \mathrm{m})$ the sizes of a pixel for the camera used in the experiments, $\xi_{\mathrm{o}}$ (from $15 \mu \mathrm{m}$ to $35 \mu \mathrm{m}$ ) and $\rho_{\mathrm{o}}\left(4 \mathrm{~g} \mathrm{~cm}^{-3}\right)$ are respectively the oxide thickness and density. In the case where the whole surface of the specimen is monitored $\left(d_{\text {specimen }}=400 \mathrm{~mm}\right.$ and $\left.d_{\text {focal }}=50 \mathrm{~mm}\right), \Delta m$ is in the range $0.27-0.64 \mu \mathrm{g}$. For oxide scales thinner than $10 \mu \mathrm{m}$ usually encountered in most applications, the sensitivity of mass change measurement can reach $0.18 \mu \mathrm{g}$ or less, which is much better than the mass resolution characteristic of usual thermogravimetric analysis. Note that it is possible to further increase the sensitivity by using a higher focal length to zoom in on the specimen. However, in this later case, the camera would not view the entire specimen surface but only one zone and the risk would then be to miss a possible spallation event occurring somewhere over the part of the specimen not filmed. Another mean to increase the sensitivity may be to monitor spall events with a camera equipped with a detector composed of a higher number of pixels of smaller size, for instance a matrix of $1600 \times 1200$ pixels as for modern facilities which will be used in our forthcoming experiments.

(a)

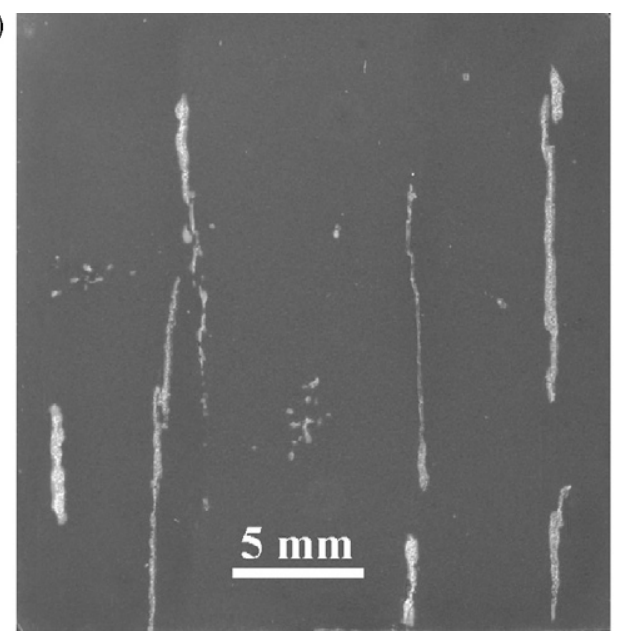

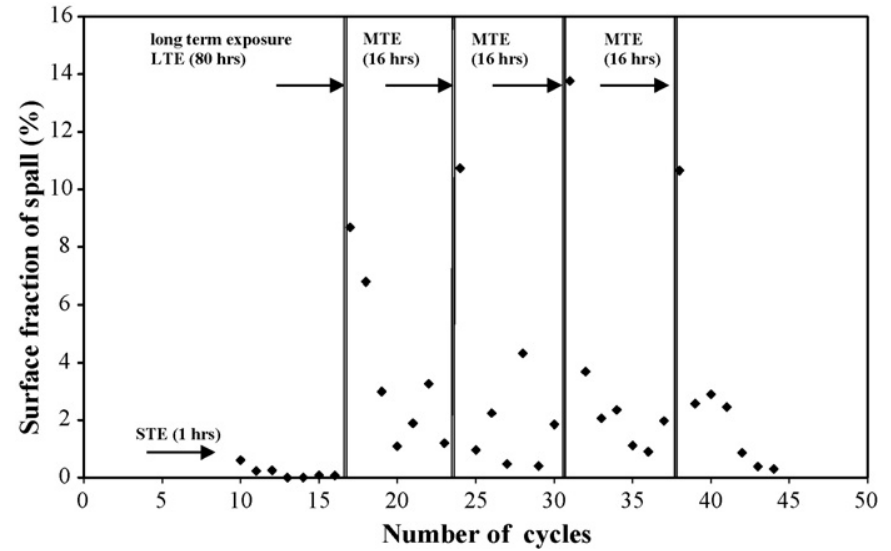

Fig. 5. Surface fraction of spall as a function of the number of cycles and cycle duration (short-term exposures (STE) are $1 \mathrm{~h}$ long, medium-term exposure (MTE) are $16 \mathrm{~h}$ long and long-term exposure (LTE) is $80 \mathrm{~h}$ long).

The same type of analysis can be performed on thermally cycled specimens. Fig. 5 shows the variation of the total spalled area determined at the end of the cooling stage for each cycle of a complex sequence of thermal cycles of varying duration. Following short-term exposure $(1 \mathrm{~h})$, the surface fraction of spall remains always lower than $4 \%$. Here again, thicker scales appear to be more prone to spallation, which results in the occurrence of larger spalled surface fraction, about $10 \%$, following longer holding time at high temperature, namely after long-term $(80 \mathrm{~h})$ and medium-term (16 h) exposures. Fig. 5 also shows that, for successive cycles of equal duration, the total spalled area decreases regularly as a function of cycle number. Such observations and analysis permit to follow the evolution of spalled fraction as a function of cycle duration and cycle number. They should be particularly useful and important for modeling cyclic oxidation behavior and kinetics [11-13].

\section{Spallation morphology and mechanisms}

More importantly, the direct observation of the overall processes of scale spallation brings new information on spallation (b)

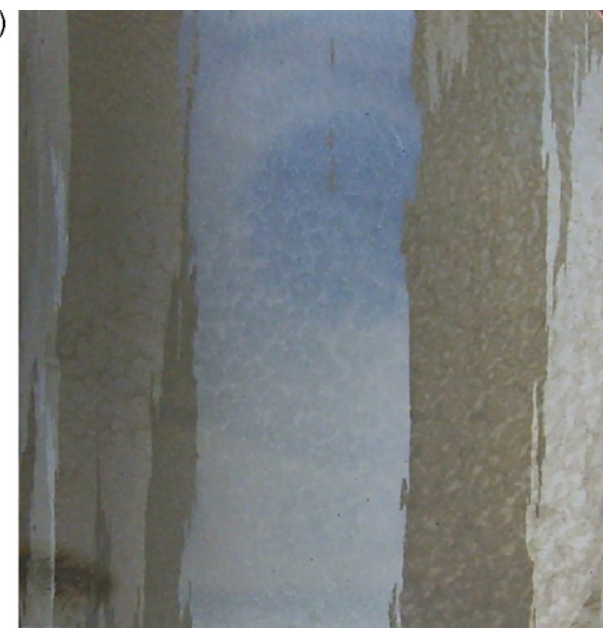

Fig. 6. First stages of scale spallation located on grain boundaries (photograph taken at $T=250{ }^{\circ} \mathrm{C}$ ) (a) and corresponding initial microstructure of substrate alloy (b). 
behavior and mechanism. All examinations and analysis performed show clearly that spallation processes are very complex and intimately related to the microstructure of the alloy substrate, namely the grain boundaries and the crystal orientation of grains The in situ observations give interesting insights in how these microstructural features influence oxide spallation kinetics and mechanisms.

\subsection{Role of the substrate microstructure}

Fig. 6a is an image extracted from a video sequence of the cooling stage of a specimen initially oxidized $384 \mathrm{~h}$ at $1300^{\circ} \mathrm{C}$. This image is typical of the very first stages of spallation of the alumina scale upon thermal shock. Clearly, the (grey-contrasted) cracks producing the damage of the scale are highly elongated and delineate the grain boundaries of the substrate alloy. Fig. $6 \mathrm{~b}$, showing the microstructure of the substrate prior to oxidation, is given as a reference to confirm that the initial spallation accurately lies along the various grain boundaries of the alloy. Further, as scale damage extends while the temperature decreases, spallation may preferentially occur over specific grains of the alloy substrate. Here again, Fig. 7a shows the initial microstructure of the substrate prior to be exposed at $1300^{\circ} \mathrm{C}$ during $384 \mathrm{~h}$. Fig. 7b is extracted from the video recording of the spallation of the thermally grown oxide at the very end of the cooling when spallation is fully completed. Spallation of the alumina scale grown over the grains on the right and left hand sides of the image is much more pronounced than that of the oxide grown over the central grain, on which it remained partly adherent to the substrate. The micrograph shows that the extent of spallation upon return to room temperature is very different from grain to grain. This preferential or inhomogeneous spalling can be also assessed through the analysis of the spallation kinetics derived for the individual grains of a same specimen first oxidized then cooled down to room temperature. Fig. 7c presents those individual spallation kinetics of the three elongated grains. Even though the critical time (i.e. the critical temperature drop) for the onset of spallation is very similar, as the result of an average oxide thickness quite close from grain to grain, the final surface fraction of spall drastically differs, typically from $20 \%$ to $90 \%$. In addition, note that the slope of the rising part of the sigmoidal curves is very different for the three grains, indicating that the spallation rate strongly depends on the substrate microstructure.

This strong behavior difference regarding spallation is undoubtedly related to the difference in surface orientation of
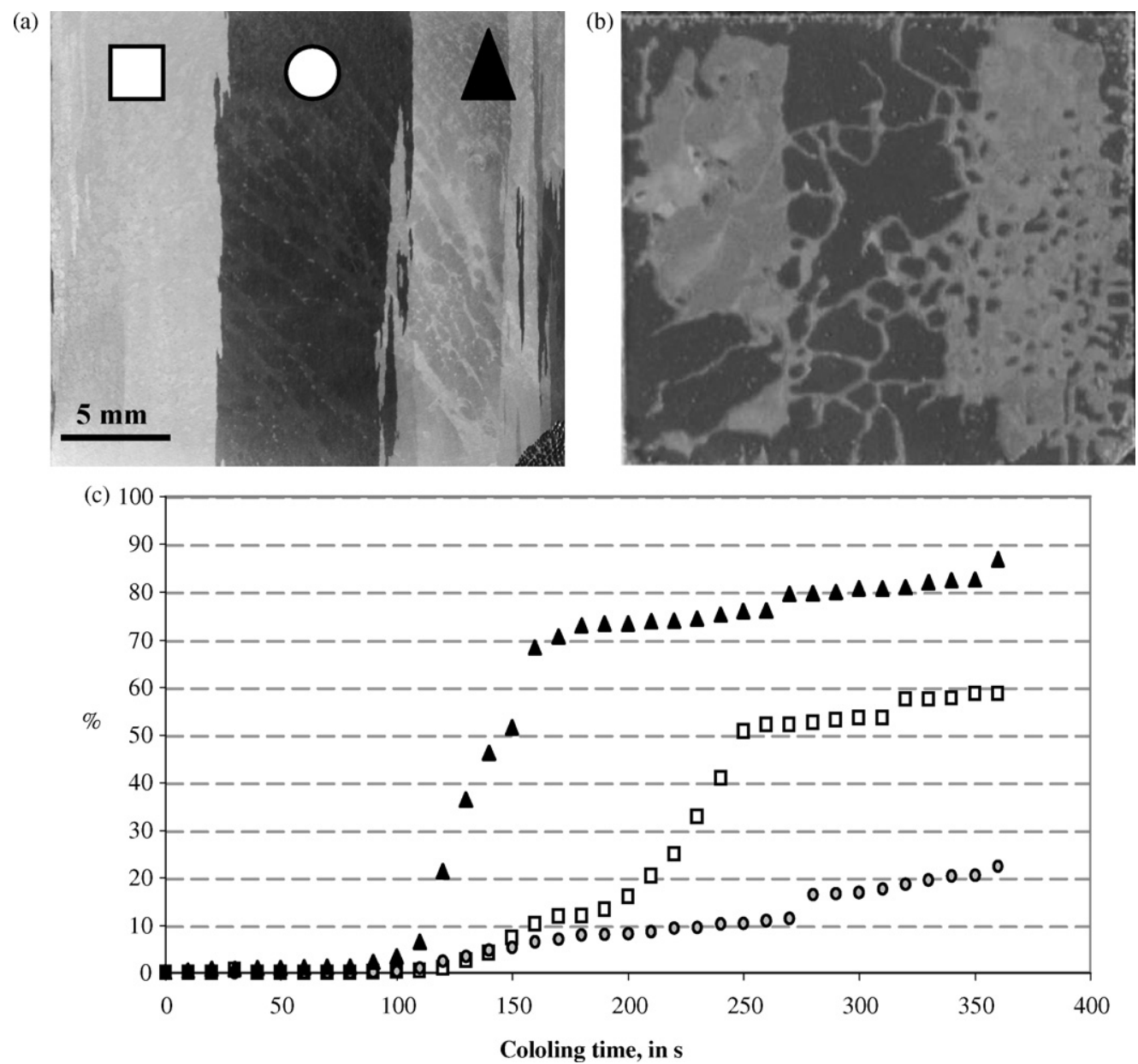

Fig. 7. Effect of grain orientation on scale spallation (PM2000 oxidized $480 \mathrm{~h}$ at $1300^{\circ} \mathrm{C}$, quick cooling (a)) initial microstructure of alloy showing three grains (labelled with circle, square and triangle), (b) specimen after spallation (photograph taken at room temperature), and (c) spallation kinetics of each grain (circle, square and triangle). 


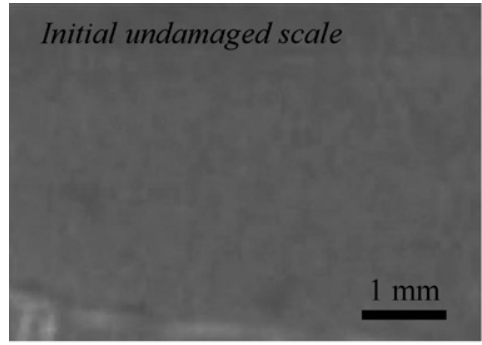

(a) $\mathrm{t}=0$

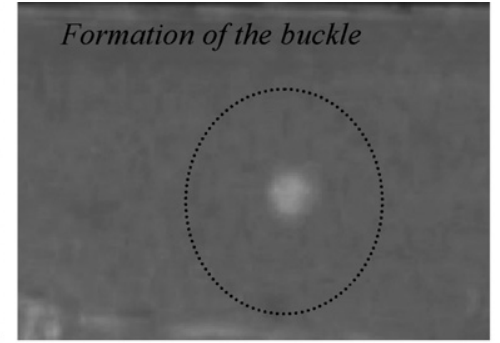

(b) $\mathrm{t}=0.04 \mathrm{~s}$

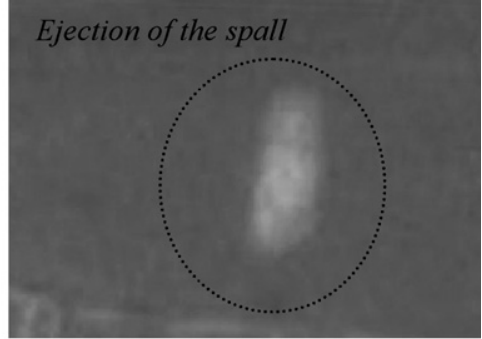

(c) $\mathrm{t}=1,2 \mathrm{~s}$

Fig. 8. Dynamic sequence of the formation and delayed ejection of an oxide buckle upon cooling PM2000 oxidized at $1300{ }^{\circ} \mathrm{C}$ during $960 \mathrm{~h}$ (photographs taken at $\left.300^{\circ} \mathrm{C}\right)$.

the various substrate grains. Several effects can explain such an influence of grain substrate orientation:

- the difference in scale growth kinetics resulting in slight different grain-to-grain oxide scale thickness;

- the difference in epitaxial relationships between oxide and metal lattices influencing the interfacial energy and the magnitude of local oxide growth stresses.

In turn, the compressive stress occurring upon cooling may vary within the oxide scale thus leading to heterogeneous spallation in relation with the substrate microstructure.

\subsection{Spallation mechanisms}

Evans has extensively described in Ref. [7] two spallation mechanisms. They correspond to two distinct routes that prevail to provoke scale spallation, namely buckling and wedging, depending on the relative strength of the oxide scale and the oxide/substrate interface. Most of the observations performed for oxidized PM2000 alloy suggest that buckling occurs more preferentially. This is particularly true in the first stages of spallation when individual isolated oxide particles detach from the substrate under the effect of the compressive stress due to the transient temperature distribution. Buckling of an oxide particle is described in the sequences in Figs. 8 and 9, each showing three frames extracted from the video recording of the cooling of specimens initially oxidized at $1300^{\circ} \mathrm{C}$, respectively, $960 \mathrm{~h}$ and $480 \mathrm{~h}$. The occurrence of buckling is established, for instance in the sequence in Fig. 8, by a thorough analysis of the contrast of the particle that spalled off. Locally, both the size of the spall damage and the image contrast gradually changes from the frame in Fig. $8 \mathrm{a}$ to $\mathrm{b}$ then $\mathrm{c}$. Indeed, the contrast is initially dark grey shade indicating a totally undamaged scale. In other words, there is no contrast difference between the zone where the forthcoming spall will form and the rest of the specimen surface. The frame in Fig. 8b, note the occurrence of a small circular zone with diameter about $500 \mu \mathrm{m}$, exhibiting a mid-grey shade contrast. This change in contrast, concomitant to the nucleation and growth of the surface defect, results from a local change in the properties of light reflection. It is assumed that this change is due to the formation of an air lamella underneath the oxide scale representative of the formation of a buckle. This initial buckle remains stable over the next 29 frames of the video recording (1.16 s) and finally detaches in the shape of a larger elongated spall, probably resulting from an additional propagation of the interfacial crack and subsequent through-thickness fracture of the oxide scale. As a consequence, in Fig. 8c, the contrast changes to a light grey shade characteristic of the full detachment of the oxide when the bare substrate is again exposed. The sequence in Fig. 9 can be regarded very similarly. Here again, the change in contrast of the zone that damages upon cooling indicates the formation of the buckle and the subsequent detachment of the spall over three frames of the video recording. In this case however, the buckle is stable during $40 \mathrm{~ms}$, over only one frame. This spontaneous buckling may be further investigated using high-speed camera to address the time scale over which the buckles form prior to the final detachment and ejection of spalls. Fig. 10 shows a cooling sequence of a PM2000 specimen initially oxidized at $1300{ }^{\circ} \mathrm{C}$ during $384 \mathrm{~h}$ recorded with a data acquisition frequency of $148000 \mathrm{images} / \mathrm{s}$, where each frames last $7 \mu \mathrm{s}$. The analysis of the contrast evolution of four successive images, corresponding to an overall $28 \mu$ s sequence, leads to the same conclusion as those drawn from sequences in Figs. 8 and 9. The formation of the buckle is completed over only one frame as indicated by the change in contrast from Fig. 10a (undamaged scale) to b. Next

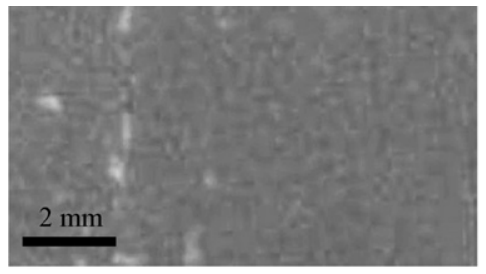

(a) $\mathrm{t}=0$

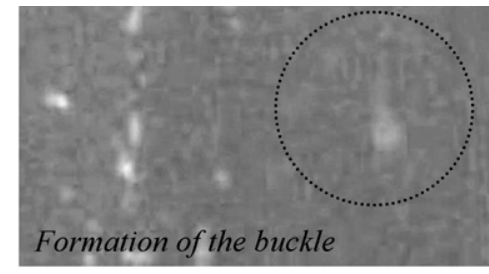

(b) $\mathrm{t}=0.04 \mathrm{~s}$

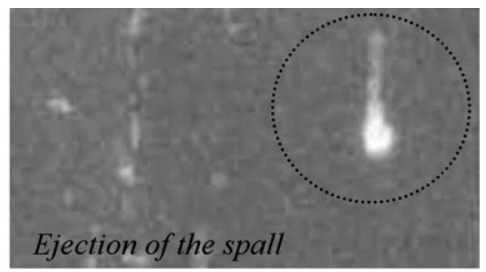

(c) $\mathrm{t}=0.08 \mathrm{~s}$

Fig. 9. Dynamic sequence of the formation and spontaneous ejection of an oxide buckle upon cooling PM2000 oxidized at $1300{ }^{\circ} \mathrm{C}$ during $480 \mathrm{~h}$ (photographs taken at $\left.260^{\circ} \mathrm{C}\right)$. 


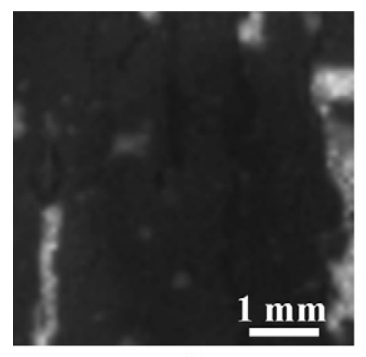

t

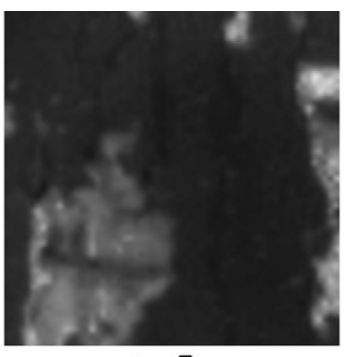

$\mathrm{t}+7 \mu \mathrm{s}$

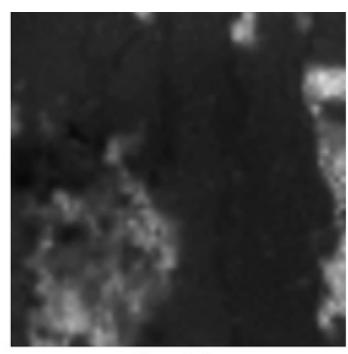

$t+14 \mu s$

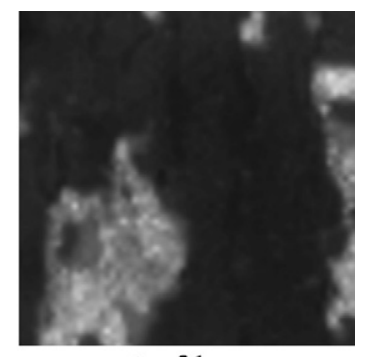

$t+21 \mu s$

Fig. 10. Dynamic sequence, recorded with a high-speed camera, of the formation and spontaneous ejection of an oxide buckle upon cooling PM2000 oxidized at $1300^{\circ} \mathrm{C}$ during $384 \mathrm{~h}$ (photographs taken at $240^{\circ} \mathrm{C}$ ).

step of the scale degradation is shown in Fig. 10c where the spall fractures in several fragments, visible owing to the very high frequency of image acquisition. While traveling upwards, these fragments partly hide the specimen surface, but it is however possible to distinguish the white contrast underneath. In contrast, corresponding to the bare substrate where the oxide spall has fully detached is clearly visible in Fig. 10d. Practically, it is not possible to decompose the mechanism of interfacial crack propagation responsible for the formation of buckles, even when using a high-speed camera (148 000 images/s). A straightforward calculation of the speed of sound in either the alloy substrate or the oxide scale shows that the ultimate crack propagation rate would be in the range $6000-9000 \mathrm{~m} \mathrm{~s}^{-1}$. In other words, typical buckles, precursor to spallation, encountered in the present experiments, with sizes in the range 100-1000 $\mu \mathrm{m}$, would form, according to this ultimate propagation rate, within some $10^{-7}$ to $10^{-8} \mathrm{~s}$.

Note that additional spallation routes can also be observed. For instance, the detachment of small oxide particles spalling in the form of localized outburst of fine powder, which generally proceeds concomitantly to the formation and the ejection of spall particles. Already reported in Ref. [10], this surface degradation mechanism is illustrated in Fig. 11a showing an image extracted from a video recording monitored with a horizontal camera viewing planes perpendicular to the specimen surface. Note the occurrence of large trails of fine volatile particles clearly visible within the three inserted white circles, while the specimen cools down and spalls off. Though not clear, the origin of such a mechanism is assumed to be relative to the high thickness of the scale and may be due to the intergranular decohesion of the small equiaxe grains of the outer part of the oxide. Indeed, SEM examinations of the fracture surface after spallation reveals the occurrence of either adhesive rupture at the oxide-substrate interface, as a consequence of buckling for instance, and cohesive rupture within the scale itself (Fig. 11b). In this later case, the rupture is brittle, either transgranular in the intermediate highly resistant columnar part of the scale, or intergranular, in the outer equiaxe part, which (a)

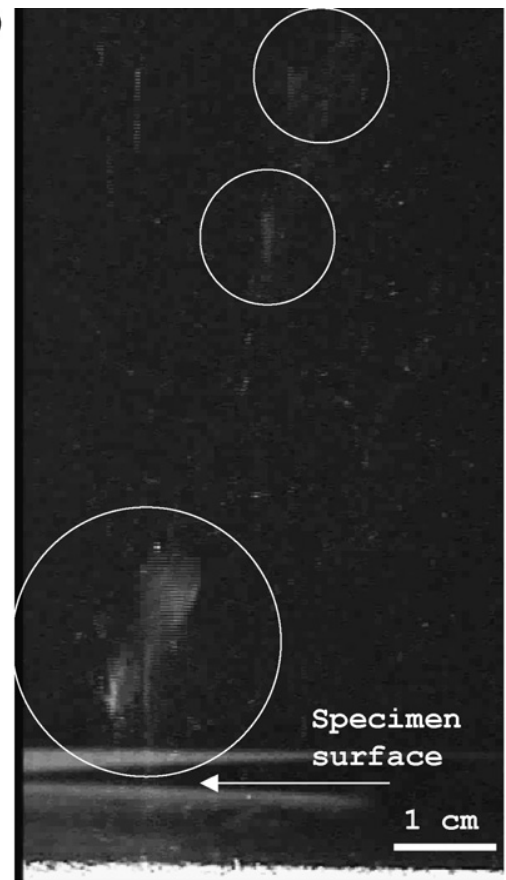

(b)

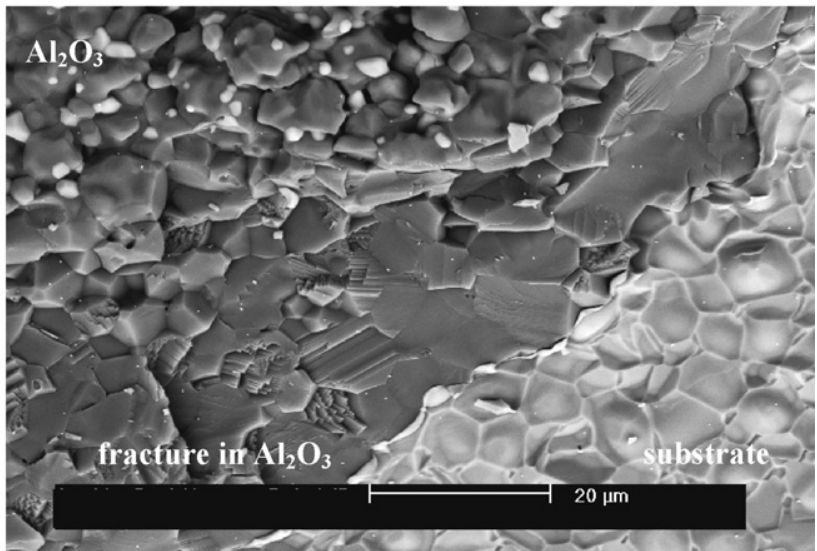

Fig. 11. (a) Fine oxide particle trails produced during cooling of an oxidized specimen and (b) morphology of spallation showing the different fracture surfaces either intergranular at the interface metal oxide (bottom right) or transgranular within the oxide (centre). 
(a)
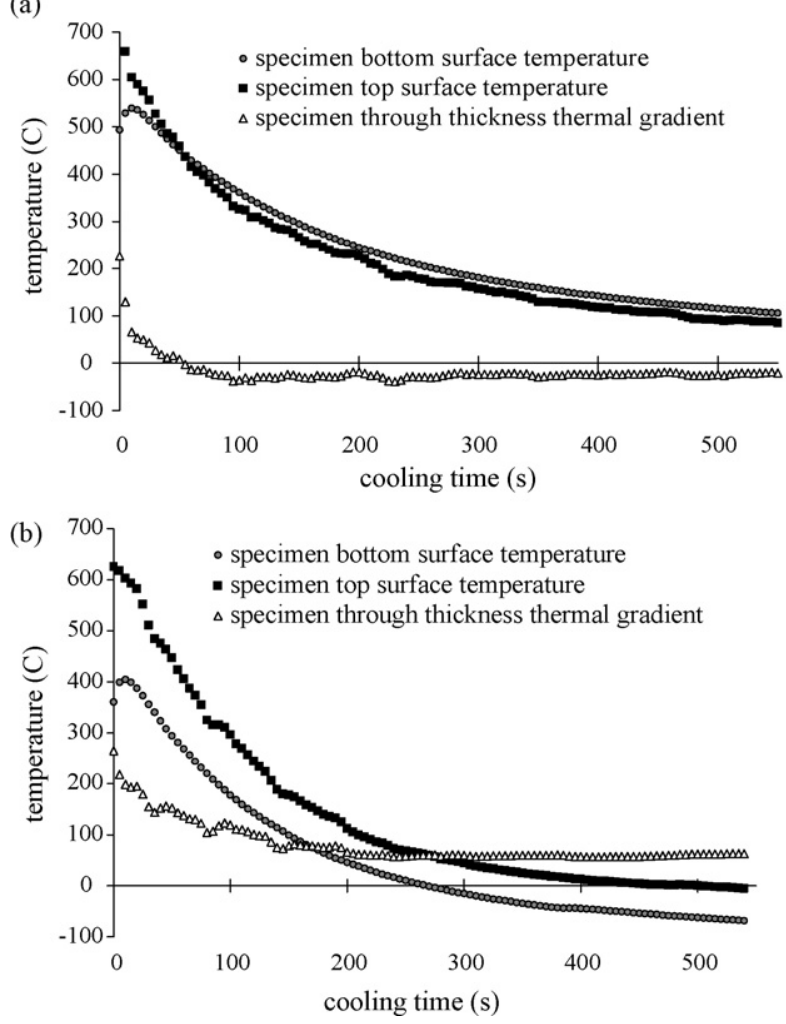

(c)

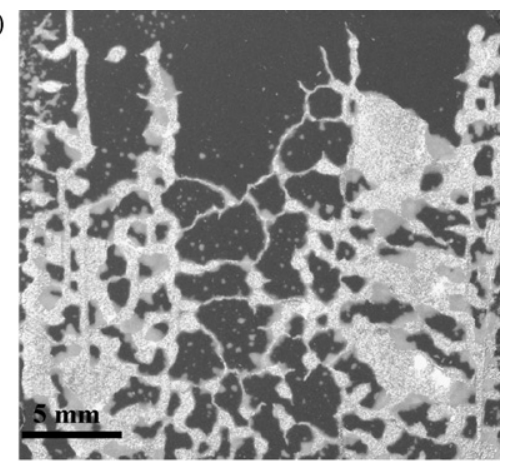

(d)

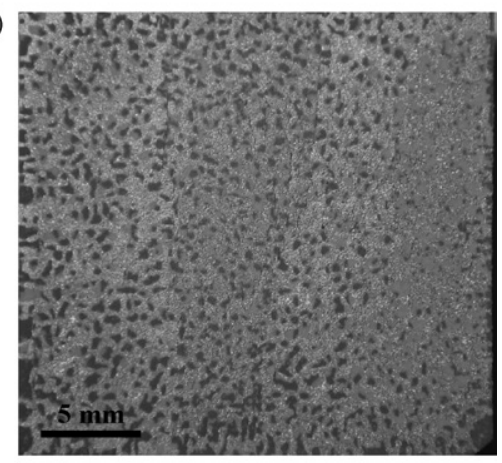

Fig. 12. Thermal gradient through the thickness of specimens cooled on top of a specimen-holder immersed in air (a) and in liquid nitrogen (b); corresponding specimen spalled surfaces ((c) refers to (a) and (d) refers to (b), photographs taken at room temperature).

could lead to the ejection of oxide particles in the form of tiny powder.

\subsection{Influence of thermal gradient}

The influence on oxide spallation of a specimen throughthickness thermal gradient during cooling is investigated by immersing the sample-holder in various cooling media, namely air, chilled water and liquid nitrogen. The bottom surface of the specimen, in contact with the sample-holder is cooled by conduction with various cooling rates, which results in the establishment of a thermal gradient through the thickness of the specimen. The temperature is simultaneously measured on the top surface of the specimen in contact with the natural air of the laboratory, and the bottom surface of the specimen, in contact with the cooled sample-holder. For two distinct experiments corresponding to cooling in air and in liquid nitrogen of $5 \mathrm{~mm}$ thick specimens, both the temperatures on the two specimen surfaces and the thermal gradient are plotted against the cooling time in Fig. 12a and b. For moderate cooling rate in air, averaging around $80^{\circ} \mathrm{C} / \mathrm{min}$ in the domain of heavy spallation, an initial thermal gradient of about $+225^{\circ} \mathrm{C}$ is established. It decreases very quickly down to a negative value around $-30{ }^{\circ} \mathrm{C}$ indicating that the top surface of the specimen is at a lower temperature than the bottom surface. In the case of a higher cooling rate in liquid nitrogen, with a mean value of $160^{\circ} \mathrm{C} / \mathrm{min}$, the thermal gradient established initially, about $265^{\circ} \mathrm{C}$, tends to decrease much more slowly and levels off around $+60^{\circ} \mathrm{C}$ to remain con- stant after about 200 s. In both cases, the temperature for the onset of spallation is determined by analysing the synchronized temperature measurement and the surface images of the specimen. The critical temperature is similar in the two cases, around $250{ }^{\circ} \mathrm{C}$. The temperature for the onset of spallation does not apparently depend on the thermal gradient and seems to be only sensitive to the oxide thickness, that is the exposure time and temperature. Indeed, for about 15 identical oxidation tests with an exposure temperature of $1300^{\circ} \mathrm{C}$ and an exposure time of $384 \mathrm{~h}$, leading to equivalent oxide thicknesses and for which sample-holder cooling was conducted either in air, in water or liquid nitrogen, the critical temperature is systematically in the range $200-300^{\circ} \mathrm{C}$.

The extent of spallation is quite different depending on the cooling medium and the induced thermal gradient through the specimen. For the examples shown in Fig. 12, the surface fraction of spall is $80 \%$ and $50 \%$ respectively for the specimen cooled in an air-chilled and in a liquid nitrogen-chilled sample holder. The analysis of the rising part of the sigmoidal-shaped spallation kinetics allows the determination of the spallation rate, defined as the surface fraction of spall per cooling time unit, for both specimens. As a matter of fact, the spallation rate is much higher for the specimen cooled according to the most severe and quick way and characterized by the highest through thickness thermal gradient. The calculated values of the spallation rate are respectively $16.8 \% / \mathrm{min}$ and $4.4 \% / \mathrm{min}$. This shows that the amount of spall produced upon thermal shock or cycling and the rate of producing those spalls strongly depend on the cool- 
ing rate, and consequently the thermal gradient, imposed to the material.

\subsection{Spallation upon thermal cycling}

The evolution of spalling during thermal cycling shows that spallation figures change as cycle number increases. Provided the oxide scale is thick enough, the very first cycles provoke an overall spallation pattern very similar to that observed upon cooling during a thermal shock. Oxide scale cracking and its initial decohesion is intimately related to the substrate microstructure and is more intense along grain boundaries, as previously discussed for spallation upon thermal shock. Healing of the scale occurs upon the subsequent oxidation during holding periods and new fresh thin oxide grows over damaged zones. This process tends to generalize as the thermal cycles cumulate and the strong relationship between the spallation and the substrate microstructure gradually declines. This results in a much more homogeneous spallation, characteristic of thin oxide scale spallation. This evolution of spallation morphology was not noticed before. It could also be related to a progressive change in substrate microstructure associated with the consumption of aluminum and the resulting interdiffusion processes linked to local change in alloy composition. Moreover, these examinations show that the area fraction of spalled oxide scale varies during the complex thermal cycles imposed to the tested specimens. After one cycle of longer holding time, the spalled fraction decreases regularly during the subsequent cycles of shorter but equal duration. Such an observation is a clear illustration of the limit of usual models of cycling oxidation assuming a constant fraction area of scale spallation.

\section{Conclusions}

The first interest of this preliminary study is to show that the simple and direct observation of the spallation during the cooling of a metallic specimen oxidized at high temperature, provides an accurate and powerful tool to determine and analyze the main features of spallation kinetics and processes. The method was used to investigate the spallation of alumina scale grown on PM2000 alloy at $1300^{\circ} \mathrm{C}$, both in condition of isothermal and cyclic exposure. In the case of cyclic oxidation, the preliminary results discussed in the paper show the benefits of monitoring in situ the scale degradation to identify important parameters such as, for instance, the fraction of spall at each cycle. The reported examinations and results show that the spallation of the alumina scales depends on commonly considered parameters such as the oxide thickness or the exposure time at high temperature but also on substrate microstructure. Generally speaking, degradation of the oxide upon cooling initially develops on grain boundaries in the early stages of scale spallation. Further, spallation develops preferentially over some grains as a function of favorable substrate crystal orientations. Spallation kinetics is also strongly grain-dependent, as both the slope of the characteristic sigmoidal curves and the final extent of scale degradation may be quite different from grain to grain. In terms of mechanisms, it is shown that the buckling mode is the most probable spallation route as indicated by the linear evolution of the critical temperature for the onset of spallation as a function of the oxidation time and the analysis of image contrasts issued from in situ real-time cooling sequences. The time scale for the formation of the buckles is extremely short and the interfacial cracks responsible for the initial scale delamination propagates within time lower than $7 \mu \mathrm{s}$ as suggests the in situ recording of scale spallation performed with a high-speed camera. Concomitant to the spallation of the oxide scale in the form of individual flat particles with various morphologies and surface size, typically ranging from $10^{4} \mu \mathrm{m}^{2}$ to $10^{6} \mu \mathrm{m}^{2}$, additional mechanism are observed. It corresponds to the local emission of fine powder assumed to be composed of the individual fine equiaxe grains of the outer part of the oxide scale.

Even though the establishment of a thermal gradient through the thickness of specimens upon cooling, have no or very little influence on the critical temperature for spallation, this provokes an increase in the final extent of spallation as well as in the rate of scale degradation.

In any case, to our point of view, it is of primary importance to investigate the cyclic oxidation behavior of oxide scales and further of coatings, under the influence of a thermal gradient. This corresponds much more accurately to the typical service conditions of most alloys. This is particularly true for thermal barrier coatings on superalloys for turbine blades for which a new automated cyclic oxidation furnace, equipped with a high resolution camera and aimed to fully control the specimen through-thickness thermal gradient, is being developed [14].

\section{Acknowledgements}

The authors gratefully acknowledge Plansee $\mathrm{GmbH}$ for providing the PM2000 alloy. They also acknowledge the help of Y. Qi, D. Adé, S. Le Roux and M. Spinu for their help and contribution to the experimental aspects of this work.

\section{References}

[1] H.E. Evans, Mater. Sci. Eng. A 120 (1989) 139-146.

[2] K. Bouhanek, D. Oquab, B. Pieraggi, Mater. Sci. Forum 251-254 (1997) 33-40.

[3] M.J. Bennett, H.E. Evans, D.A. Shores, Mater. High Temp. 12 (1994) 127-133.

[4] M. Schütze, W.J. Quadakkers (Eds.), Proceedings of the EFC Workshop No. 27, Cyclic Oxidation of High Temperature Materials, Frankfurt, 1999.

[5] D. Monceau, D. Poquillon, Oxidat. Met. 61 (2004) 143-163.

[6] S. Baleix, G. Bernhart, P. Lours, Mater. Sci. Eng. A 327 (2002) 155-166.

[7] H.E. Evans, Int. Mater. Rev. 40 (1995) 1-40.

[8] J.R. Nicholl, H.E. Evans, S.R.J. Saunders, Mater. High Temp. 14 (1997) 5-13.

[9] M. Schutze, Mater. High Temp. 22 (2005) 147-154.

[10] P. Lours, Y. Le Maoult, D. Add, B. Pieraggi, Mater. Sci. Forum 461-464 (2004) 639-645.

[11] J.L. Smialek, Acta Mater. 51 (2003) 469-483.

[12] J.L. Smialek, Acta Mater. 52 (2004) 2111-2121.

[13] D. Poquillon, D. Monceau, Oxid. Met. 59 (2003) 409-431.

[14] J. Sniezewski, Y. Le Maoult, P. Lours, HTCPM, 2008 (forthcoming), in press. 